\title{
ANAEROBIC TREATMENT OF SLUDGE, INDUSTRIAL WASTE WATER AND INDUSTRIAL WASTE FROM FOOD INDUSTRY
}

\author{
Björn Rosén \\ Scanvironment \\ Håkan Eriksson \\ Kalmar Vatten\&Renhållning \\ Sweden
}

\section{ABSTRACT}

The use of biological anaerobic treatment for sludge digestion in treatment plants has a long operational record. The result is a lower amount of stabilised sludge and a considerable energy output, as heat and possibly also electrical energy. In industrial waste water treatment, anaerobic processes have also been used quite a long period, especially in food and pulp and paper industries. The anaerobic treatment of organic waste from industries or municipal waste, is a more recent application.

The paper presents a summary of used anaerobic technology, with a special case from the Kalmar waste water treatment plant, where the two existing sludge digesters are upgraded to termophilic anaerobic treatment, one unit $t$ be used for sludge and the other, separately, for organic waste from food industry and manure from farms. 


\section{INTRODUCTION}

Industrial waste waters, sludge from waste water treatment plants, or organic waste include a high amount organic matter, which must be degraded into inorganic or less obnoxious organic matter. One possibility is the oxidation, using aeration for biological degradation. Another possibility is using anaerobic biological treatment, which for high concentrations of organic matter has a lot of advantages. Some majer aspects of anaerobic and aerobic treatment are summarised below:

\begin{tabular}{|l|l|}
\hline Anaerobic processes & Aerobic processes \\
- Production of energy - methane gas & - Consumption of energy - electricity \\
- Low operational costs & $\begin{array}{l}\text { - High operational costs } \\
\text { - High investment costs }\end{array}$ \\
- Long start-up period & $\begin{array}{l}\text { - Low investment costs } \\
\text { - Sludge - better stabilisation }\end{array}$ \\
- Longer detention time & $\begin{array}{l}\text { - Water - lower organic matter in effluent } \\
\text { - Production of ammonia and hydrogen- } \\
\text { sulphide (toxic or inhibiting) }\end{array}$ \\
\hline
\end{tabular}

\section{OVERALL APPROACH}

A good operating treatment plant is never a goal. It is an imperative means to reach the basic goal, which most often is a well defined function, i.e. a certain amount of water or waste water with the required quality, supplied at the lowest possible total cost, i.e. the sum of capital and operational costs.

This fact must always be kept in mind, not least when evaluating all anaerobic treatment systems, as the investment cost are considerably higher than for aerobic systems. The operational costs, on the other hand, are very favourable for the anaerobic systems, as more energy is produced than used, and the sludge production is much lower.

\section{ANAEROBIC PROCESSES FOR SLUDGE AND WASTE WATER TREATMENT}

\section{General on Anaerobic Treatment}

The anaerobic treatment is a two-stage biological process, even if the two processes often take place in the same reactor. If organic acids are not present, acidification or hydrolysis must at first take place, transforming more complex organic matter into volatile fatty acid (VFA). In the next stage, the methane fer- 
mentation, other micro-organisms transform organic acids into biogas, a mix of methane and carbon dioxide. In many cases, it is advantageous to include the two processes in separate reactors for optimal results, i.e. for hydrolysis respectively methane fermentation.

The anaerobic process has two different optimal temperatures, mesophilic or 33$37^{\circ} \mathrm{C}$, compared to thermophilic or $50-55^{\circ} \mathrm{C}$. The mesophilic process is generally regarded as being more stable, as a wider spectra of micro-organisms are present. Sometimes, however, another temperature range will give better results. At Stora Hylte Pulp and Paper mill, Sweden, practical experience shows optimal results on evaporate condensate of some $43^{\circ} \mathrm{C}$.

The thermophilic process is expected to give more rapid degradation and methane fermentation, having, however, a more narrow operational optimal range, process- and temperature-wise.

\section{Sludge Digestion}

Anaerobic sludge digestion is normally designed for thickened raw sludge and excess sludge from the biological treatment process, with an optimal dry solids content of 5-8\%. Up to some $50 \%$ of the organic matter will be transformed into biogas, with 65-80\% methane concentration. As a rule, some $1 \mathrm{me}^{3}$ of biogas will be produced by $1 \mathrm{~kg}$ organic matter removed. In northern Europe, approximately $1 / 3$ of the energy is needed for heating the sludge in the mesophilic range.

The design of digesters is depending on the target for the process. If the target is optimal gas production per volume, some 8-10 days detention time is sufficient. If on the other hand, sludge stabilisation is the target, some 15-25 days are required. In different countries, different standards are being used. In Germany, the tendency is towards long detention time, even 20-30 days. In USA, on the other hand, 7-10 days are often used. In Sweden, a middle road is being used, with a detention time of some 12-15 days. All figures above are valid for the mesophilic digestion.

Also the practical design is different. In Germany, complex, egg-formed digesters are often being used, with gas or pump mixing. In USA, large, fairly flat reactors are being used, with lateral mechanical mixers, or gas mixers, and sometimes plastic top cover for gas collection. In Sweden, cylindrical digesters with flat bottom and roof are being constructed, having a depth to width ratio of 0.8 1.2 , using vertical mechanical mixers with high pumping capacity.

The recent development has shown improved performance with a short hydrolysis stage, 1-2 days detention time, preceding the methane fermentation tank, with some 10 days' retention time.

Another design criteria is the amount of organic dry solids per volume unit and time. Too much organic matter might lead to too rapid acid fermentation and $\mathrm{pH}$-drop, which will inhibit the methane fermentation, all resulting in large operational problems. Continuous loads up to $4 \mathrm{~kg}$ organic dry solids per day and 
$\mathrm{m}^{3}$ of volume will normally not give any problems. In case of possible short-term overload, the $\mathrm{pH}$ and particularly the VFA concentration must be carefully controlled to avoid excess acid fermentation. A change in the gas mix of carbon dioxide and methane will also indicate excess acid fermentation.

\section{Anaerobic Waste Water Treatment}

Anaerobic treatment of waste water is usually the first biological stage in a multistage process, followed by some sort of aerobic treatment, as not only methane is being formed in the process. Matter containing nitrogen or sulphur will be reduced into ammonia and hydrogen sulphide, which cannot remain in the effluent from a plant, and must consequently be (biologically) oxidised before discharge.

Both ammonia and hydrogen sulphide will be inhibiting the methane fermentation. When, for example, applied to evaporate condensate from the pulp and paper industry, concentrations over $150 \mathrm{mg} \mathrm{H}_{2} \mathrm{~S} / \mathrm{l}$ will disturb the process. In such a case ferric chloride, or possibly micro-organisms which transform $\mathrm{H}_{2} \mathrm{~S}$ into elementary sulphur, must be added.

Depending on local energy prices, temperature of the raw waste water and the organic content, the process 'pays off' from an average COD-content of some $2.000 \mathrm{mg} / \mathrm{l}$.

\section{The Contact Process}

The contact process can be regarded as an anaerobic activated sludge process, i.e. with a contact reactor, followed by a separation stage, of ten lamella settling, for the recirculation of sludge. The contact process is designed for some $2-3 \mathrm{~kg}$ COD per $\mathrm{m}^{3}$ and day, which will give much larger volumes than for fixed bed reactors. On the other hand, the volume marginal cost is of ten relatively cheap, compared the more sophisticated processes presented below.

The greatest problem with the contact process is the separation and recycle of sludge, as sometimes the anaerobically formed biological flocs are not easily separated, which may lead to loss of sludge or micro-organisms, thus inhibiting the process.

\section{The Fixed Bed Processes}

Similar to aerobic treatment systems, fixed bed reactors have a proven higher capacity as well as better process stability and performance. The media is often some plastic component, on which the micro-organisms grow, immobilised compared to the contact process. The risk for losing sludge is decreased, and though the media might be expensive, future development will most probably give most cost-effective fixed bed reactors.

Depending on the characteristics of the media, the fixed film reactors are designed for some 5-10 kg COD per $\mathrm{m}^{3}$ and day. 


\section{UASB-Reactors}

The upflow anaerobic sludge bed (UASB) reactor might be regarded as a fixed bed process. The inlet waste water is fed uniformly at the bottom part of the reactor, passes upwards through a sludge blanket on its way to the three-phase separation unit at the top, for collecting gas, treated water and recirculating sludge back to the sludge blanket. At some installations, anaerobic sludge granules will occur, having a very high settling velocity and high methane fermentation ability.

The UASB-reactors are is designed for some 5-15 kg COD per me and day, the higher value when granules are being used.

This type of reactors is emanating from Holland, and has a proven record for waste waters from food industries, and re-use paper mills. The problem is that sometimes the granules do not appear, and the mechanisms controlling granulating are not satisfactorily known. Sometimes the supplier of the process include granules from other plants for 'seeding' at start, not always successful for a longer period.

\section{Summary Design Parameters}

The different anaerobic processes are generally designed, based on the following criteria.

\begin{tabular}{|c|c|c|c|}
\hline & Contact process & UASB & Fixed bed reactors \\
\hline Detention time & $24-48 \mathrm{~h}$ & $5-15 \mathrm{~h}$ & $5-10 \mathrm{~h}$ \\
COD-load, $\mathbf{k g} / \mathbf{m}^{3} * \mathbf{d}$ & $2-3$ & $5-15^{*}$ & $5-10 \mathrm{~h}$ \\
\hline
\end{tabular}

* the higher value is valid when granules are being formed

All design values above include the overall anaerobic process, i.e. including any hydrolysis stage. It should be stressed that the values above might be higher or lower for a particular waste water. Consequently, laboratory tests, and sometimes pilot tests are recommended if the characteristics of the waste water is not satisfactorily known.

Particular care must be taken to the start-up and fine tuning of the process, which normally will take a long time.

\section{Gas production}

The amount of methane which is formed, is dependant on the characteristics of the waste water, theoretically resulting in 0,35 me methane per $\mathrm{kg}$ COD reduced. For the Stora Hylte contact process plant, the gas production is $0,15-0,20 \mathrm{~m}^{3}$ methane per $\mathrm{kg}$ COD reduced. In the MoDo Domsjö, Sweden, also using the contact process for evaporate condensate, the gas yield is some $0,25 \mathrm{~m}^{3}$ methane per kg COD reduced. The better result may be explained by better sulphide control, by recovering sulphur from the recirculating biogas in a sodium-hydroxide scrubber. The sodium sulphide formed is then used in the pulping process. 


\section{ANAEROBIC TREATMENT OF ORGANIC WASTE}

The anaerobic process is also able to handle organic waste, preferably from food and agriculture industry. By choosing the right pre-treatment, and source of waste, possible problems will be overcome.

\section{ENERGY GENERATION}

The energy generated can be used as heat, with the best economy when biogas can be substituting oil or natural gas. Sometimes, the necessary heating of the sludge might be arranged by using waste heat or by using a heat pump or heat exchangers with energy collected from the effluent treatment plant.

Another possibility is using the biogas in electrical generators, where up to $40 \%$ is converted into electricity, and some 50-55 \% is available as heating energy, some half of which is needed for sludge heating, when sludge digesters are being used.

\section{COST ASPECTS}

The major influence on the final cost is the investment and financial costs, as well as the actual operation costs for e.g. energy, per $\mathrm{kWh}$ or ton oil, chemicals, manpower and sludge handling and disposal. An example is given below.

\section{CASE STORY:}

\section{CTMP Waste Water - Comparison Anaerobic and Aerobic Processes}

At SCA Östrand, the waste water from the CTMP (chemical-thermo-mechanicalpulp) process is being treated in a multi-stage process, starting with detoxification and hydrolysis stages, followed by a hybrid anaerobic contact/ UASB-reactor and activated sludge process. The COD-load is $30 \mathrm{t} / \mathrm{d}$, or 4 $\mathrm{kg} / \mathrm{m}^{3 *} \mathrm{~d}$. The COD-reduction is some $60 \%$. The gas yield is some $0,2 \mathrm{~m}^{3}$ methane per $\mathrm{kg} \mathrm{COD}$ reduced, or in total $2.200 \mathrm{~m}^{3} / \mathrm{d}$, corresponding to some $2 \mathrm{~m}^{3}$ of oil per day. The gas is substituting oil and is thus very efficiently being used. Investment costs in total was some 45 MSEK.

At another CTMP-mill, VagCel, Sweden, a multi-stage aerobic process was chosen, partly based on the experience from the activated sludge stage at Östrand. The investor preferred a low investment and accepted the higher operational costs.

Pre-precipitation, 2-stage activated sludge and post-precipitation, resulted in an investment only of some $15 \mathrm{MSEK}$, though not built at the same high quality as at SCA Östrand. On the other hand, the difference in energy consumption was some $3.500 .000 \mathrm{kWh} / \mathrm{a}$.

Similar removal results are being obtained at both plants. An approximate comparison of capital and major operational costs (energy, sludge handling) is given below: 


\begin{tabular}{|lrl||}
\hline Difference, capital cost (corrected ) 28 MSEK, 15\% & 4.200 .000 & SEK \\
\hline Difference, electrical energy, 0,3 SEK/kWh & -1.050 .000 & SEK \\
\hline Difference, 'oil' production $750 \mathrm{~m}^{3} / \mathrm{a} \cdot 2.500 \mathrm{SEK} / \mathrm{m}^{3}$ & -1.850 .000 & SEK \\
\hline Difference, sludge handling and disposal & 1.200 .000 & SEK \\
\hline SUM & $\approx+1-\mathbf{0}$ & SEK \\
\hline
\end{tabular}

The overall result is roughly the same. With other financial and operational costs, the result might have been to the clear advantage of one of the processes.

\section{CASE STORY: ORGANIC WASTE, KALMAR, SWEDEN}

\section{Kalmar Waste Water and Anaerobic Treatment Plant, for Food Industry and Farmer Waste}

Kalmar University started 1990 a study on the anaerobic treatment of waste and waste water from chicken slaughterhouses, in close co-operation with the Kalmar waste water treatment plant. The study was financed by the Swedish National Development Board (STU/NUTEK). The general idea was to integrate the treatment of waste water and waste for optimal energy production. The most interesting part of the study showed that some $35 \%$ of the insoluble COD in the organic waste was transferred in a hydrolysis stage into soluble COD, of which some 95 $\%$ was fermented into methane.

Partly as a result of the above works, a thorough study was carried out in 1991 to 1993 in Kalmar, in order investigate the possibilities of building a plant for treating waste from food industry in the Kalmar region. After evaluation of different possibilities and locations, the decision was taken not to invest in any plant, as the expected cost of such a plant, approximately 100 MSEK, was regarded as too high.

During 1996 the waste water treatment plant in Kalmar was under construction, for upgrading to include nitrogen removal and for modernisation. The upgrading also included a new part for external sludge and organic waste collection, mostly blood from the local slaughterhouse. During the construction of the plant, the idea of possible anaerobic waste treatment was brought to life again. The main reason for taking anaerobic treatment into consideration was the fact that the existing plant had two digesters, with low organic load.

It was decided to further evaluate the possibilities to use one of the digesters for organic waste from the food industry and also include some waste from local shops and restaurants. One of the main reasons for such a solution was also to enable to fulfil the Kalmar municipality's decision to increase the circulation of organic matters and fertilisers in the whole society (part of the Kalmar Agenda 21 work). 


\section{Target for the Project}

When evaluating the possibilities in upgrading the plant for separate processing of waste from the food industry, certain targets were set, which all should be fulfilled, as follows:

1. The plant should be located at the existing waste water treatment plant, and operation of the plant should be carried out with existing personnel.

2. The chosen technology should be as simple as possible and easy to maintain

3. The plant should not be dependant of a certain substrate

4. The plant should be very flexible.

5. Both liquid and solid waste should be possible to treat.

6. The municipal sludge should be possible to treat separately.

7. The plant should be profitable in 7 years' time.

8. All residues from the plant will be used as fertilisers for agriculture purpose.

9. The produced gas should be used as fuel for the municipality's cars and trucks

\section{Present and Future Operation}

The two totally mixed digesters are at present being operated in series, and the volume in each tank is $1800 \mathrm{~m}^{3}$. Both are used for municipal sludge, and operated at the thermophilic range, some $37^{\circ} \mathrm{C}$. The specific organic load is only $1,0-$ $1,5 \mathrm{~kg}$ VS per $\mathrm{m}^{3}$ and day.

It is possible to treat all the municipal sludge in one digester, particularly if the process is changed from mesophilic to thermofilic digestion. Thus the other digester can be used for the purpose of treating waste from the food industry. The change from mesophilic to thermophilic digestion can be carried out with very small investment costs. The major activities to be carried out are:

- Changing to parallel reactors.

- Improving sludge thickening to increase the dry solids content to the municipal digester.

- Modifying the heating system.

- Installing improved heat recovery.

- Changing the gas system for higher content of humidity, because of the higher process temperature.

Changing the sludge digestion from mesophilic to thermophilic process, as well as creating another mix of micro-organisms in the digesters, must be carried out under a longer period of time. The load of the reactor has to be increased very slowly. The start-up should be possible to carry out without any disturbance of the normal operation of the plant. The other reactor will then be available as a separate line for anaerobic treatment of waste. 
The suitable mix of waste which possible to treat is consisting of approximately 10.000 ton of food residues and approximately 20.000 ton of liquid manure from farmers. The payment ability for the waste delivered to the plant is expected to be very good, as contracts already have been signed.

The process is expected to be very stable, thanks to the buffer/mixing tank, and the balanced supply of manure and organic matter.

Table 1. Technical data for thermophilic digestion of manure and residues from food in industry in existing digester, volume $1.800 \mathrm{~m}^{3}$.

\begin{tabular}{||c|c|r|c||}
\hline Process & $\begin{array}{c}\text { Single stage, wet, continuous, } \\
\text { totally mixed, thermophilic }\end{array}$ & Detention time & 21 days \\
\hline DS inlet & $11,5 \%$ & Gas production & $1.400 .000 \mathrm{Nm}^{3} / \mathrm{a}$ \\
\hline DS, ou tlet & $6,5 \%$ & Methane & $55-75 \%, 70 \%$ average \\
\hline Reduction & $60 \%$ of organic matter, average & Energy & $10 \mathrm{GWh} / \mathrm{a}$ \\
\hline
\end{tabular}

\section{Process Description}

The overall waste handling is divided into five different parts: collection, hygienisation, digestion, waste treatment and finally gas treatment.

The solid waste and solid manure will be collected in a building including a collection pocket, where the supplied waste automatically is measured. The liquid waste is also received in this building and the supply measured. The solid waste will pass a metal detector before being macerated in to pieces of maximum 5 $\mathrm{mm}$ particle size. After the macerating, it is transported into a mixing tank were it is mixed with the liquid waste, e.g. blood and liquid manure. The mixing tank is also a buffer tank for the process and is totally mixed. From the mixing tank all the substrate is transported to the hygienisation part.

The hygienisation part consists of three tanks, each $50 \mathrm{me}$, used as a continuous process. The substrate is having a detention time in the hygienisation for approximately 6-8 hours at a temperature of $55 \mathrm{BC}$. The plant equipped with several heat exchangers for recovering the energy.

The hygienisated substrate is pumped into the digester, where the detention time is approximately 21 days. The residue from the digester is pumped into a storage tank of $600 \mathrm{me}$, and is a high quality fertiliser, which can be used directly by the local farmers.

At present, the existing digesters are producing some 1.000 .000 mé biogas per year, which is corresponding to an energy amount of $6,5 \mathrm{Gwh}$ or some 650 mé of diesel fuel per year. The total amount of biogas produced at the plant, after changing to thermophilic digestion, will be approximately. $2.400 .000 \mathrm{mez}^{3}$ per 
year, i.e. an increase of the production of $140 \%$, compared to the present operation, or in total some $1.65 \mathrm{Gwh}$ per year,.

In order to get an economically sound business in the operation, the value of the gas must be sufficiently high. That will be achieved by the refining of the gas into a substitute for petrol, by a gas cleaning facility. The equipment will clean the gas to $98 \%$ of methane and compress it to 250 bar. The technology for using biogas is nearly the same as for natural gas. The gas can be used by buses or cars.

\section{Economical Evaluation}

The total investment cost for the plant is 23,5 MSEK, compared to the originally discussed solution with new reactors, 100 MSEK. The split up of the investment is as follows:

$\begin{array}{lrl}\text { food industry waste treatment } & 20 & \text { MSEK, } \\ \text { gas treatment } & 3,5 & \text { MSEK }\end{array}$

\section{CONCLUSION}

The positive and long time experience in anaerobic sludge treatment has successfully been transferred into anaerobic treatment of waste waters with high content of organic matter.

For organic waste, the future seem to be similarly bright, though long-time experience still is lacking. The cases shown for waste water and organic waste above stresses the importance of an overall view and long-term perspective. The anaerobic treatment of organic waste will give an economic alternative for re-use instead of disposal, which will be politically impossible in the future.

\section{REFERENCES}

Angelidaki, R.I. Termofil rötning av avloppsslam och slakteriavfall i Kalmar. Internal study, carried out by the University of Copenhagen 1996.

Ling, D. Rötning av slakteriavfall från kycklingindustrin. Examensarbete LTH/Kalmar University 1991

Rosén, B. Anaerobtechnik in der Papier- und Zellstoffindustrie. ATV-Seminar 02/93, Anaerobtechnik bei der Abwasserbehandlung. Dresden 25.10.1993 